\title{
Histological and electron microscopic study of the postulated protective role of green tea against DEHP liver toxicity in mice
}

\author{
Abeer A. Khalik $\mathrm{M}^{1 *}$ Nermine Nosseir ${ }^{2} *$ Mahmoud Salah $\mathrm{K}^{1}$ and Mona K. Tawfik ${ }^{3}$ \\ 1. Department of Histology. ${ }^{2}$ Department of Anatomy \& 2. Department of Pharmacology. \\ Faculty of Medicine. Suez Canal University, Ismailia. Eygpt.
}

\begin{abstract}
SUMMARY
Di(2-ethylhexyl)phthalate [DEHP] is a plasticizer (softener) used to increase the flexibility of polyvinyl chloride (plastic). Animal studies following acute and chronic exposure of DEHP show several toxic changes in many organs including the liver. There have been no studies of compound specific techniques for reducing DEHP body burden. A study of the impact of dietary modifications (increased intake of antioxidants, zinc and glutathione precursors, and decreased dietary fat) on the effects of exposure to DEHP might be useful. Antioxidants effect of green tea was confirmed in many studies as a substance that protects the body from free radicals against degenerative changes by minimizing the amount of damage. This study was performed to evaluate the postulated protective effect of green tea against DEHP Liver toxicity in the mice on histological and ultra structural level. Results showed no significant differences in the mean of hepatocytes affection regarding necrosis or hydropic degeneration between $2^{\text {nd }}, 3^{\text {rd }} \&$ $4^{\text {th }}$ groups. Marked increase in amount of collagen fibers between hepatocytes and marked depleted glycogen contents in many hepatocytes were detected in $2 \mathrm{nd}, 3^{\text {rd }} \& 4^{\text {th }}$ groups. Ulrastructral changes of the hepatocytes showed degenerated membranous organelles, destructed nuclear membrane and cytoplasmic necrosis in $2^{\text {nd }}, 3^{\text {rd }} \& 4^{\text {th }}$ groups. Many fat globules detected in the $3^{\text {rd }}$ group were diminished in the $4^{\text {th }}$ one. In conclusion, in-significant difference in hepatocytes affection existed between green tea control group, DEHP group \& green tea/DEHP group. It is concluded that green tea has no antioxidant role against DEHP liver degeneration, in contrast it may have an oxidant role; further studies are needed.
\end{abstract}

[Afr J Health Sci. 2007; 14:19-36]

\section{Introduction}

Di (2-ethylhexyl) phthalate is a manufactured chemical that makes plastic more flexible. It is also called DEHP. DEHP is a colorless liquid with almost no odor. It is everywhere in the environment because of its use in plastics it is used in plastic toys, shower curtains, adhesives, coatings [1]. We can be exposed to DEHP by using medical products packaged in plastics, eating foods packaged in plastics, breathing indoor air where DEHP is released or from intravenous tubing used extensively as for kidney dialysis. DEHP was found to be one of the more toxic phthalates [1].

The route of exposure is through inhalation, dermal, oral and intravenous route. The oral route is the most common way of exposure. Single oral doses up to $10 \mathrm{~g}$ DEHP are not lethal to humans, so DEHP is very unlikely to cause acute mortality in humans; the toxic effects are likely to be through chronic exposure [2].

Human data indicate that gastrointestinal absorption of DEHP and its metabolites might amount to approximately $20-25 \%$ of an orally administered dose [3]. DEHP is absorbed primarily as MEHP and 2-ethylhexanol, along with small amounts of unhydrolysed DEHP, DEHP is hydrolyzed in the gastrointestinal tract by a pancreatic lipase [4]. DEHP is lipophilic and tends to accumulate in adipose tissue [5]. The liver is one of the common sites of DEHP metabolism and utilization after oral exposure [3]. Oral exposure of rats and mice to DEHP result in marked increase in liver mass and increase in relative liver weight [6]. Hepatic hyperplasia appears to be the initial physiological response to DEHP [3,7]. Morphological changes which were observed in the livers of treated rats included fat deposits in the periportal area [8]. Liver cells became enlarged and lipofuscin deposits accumulated indicating that peroxidation of cellular lipids had occurred [4]. There was a definite increase in hepatic peroxisomes in the centrilobular and periportal areas of the liver and there was often an increase in number of mitochondria [6].

There have been no studies of compound specific techniques for reducing DEHP body burden. A study of the impact of dietary 
modifications (increased intake of antioxidants, zinc and glutathione precursors, and decreased dietary fat) on the effects of chronic exposure to DEHP might be useful [6]. Antioxidants effect of green tea was confirmed in many studies as a substance that protects the body from free radicals against degenerative changes by minimizing the amount of damage [9]. Green tea contains water, proteins, carbohydrates, minerals, vitamins and polyphones of the falconoid type. The major flavonoids in green tea are catechins, which constitute about one third of its total dry weight $[9,10]$. Three principal tea flavanols epigallocatechin-3-gallate (EGCG), epicatechin gallate (ECG), and epigallo catechin (EGC)] are present in fresh tea [11]. EGCG is the major catechin present (more than 50\%). So, The chemo preventive effect of green tea have been largely attributed to anti-oxidative and anti-inflammatory activities of its polyphenolic constituents as the [epigallocatechin-3-gallate (EGCG) [12]. This study was designed to see if green tea or its antioxidant components could reduce DEHP burden on the liver of mice.

\section{Materials and Methods}

Twenty-four healthy mature male white mice each weighing 20-30gm was used in this study. After acclimatization, the animals were randomized and classified into 4 groups each group containing 6 mice: The first Control group were fed standard diet and water ad-libitum while the green tea control group were given green tea as drinking water. The animals in the third group ([DEHP] group) received [DEHP] only while animals of the fourth group (green tea/ [DEHP] group) received green tea \& [DEHP]. Green tea was given at $2 \%$ concentration in the form of tablets dissolved in drinking water, starting one week before the beginning of the experiment. Di [2ethylhyexyl]phthalate [DEHP] were received as repeated oral dose of $50 \mathrm{mg} / \mathrm{kg} /$ day for 3 consecutive days (by intra-gastric tube).

The animals in all groups were killed by decapitation 60 minutes after $3^{\text {rd }}$ [DEHP] administration. The abdomen was opened in each mouse and part of the liver were excised and fixed in neutral buffered formaline for light microscopic study. Specimens were processed for paraffin sections $(4 \mu \mathrm{m})$ and stained with hematoxylin and Eosin (H\&E) and with Masson's Trichrome and periodic acid Schiff (PAS). The H\&E sections were used for quantitative analysis of the degree of affection of hepatocytes [13]. The following degree was used for quantification: no affection and mild, moderate \& severe affection as shown in Table 1. The relative frequency of each degree was counted in 10 high power fields in three sections from each of the animal groups. All values were expressed as mean. Chi-square test was used to compare each degree of affection in each two groups. $\mathrm{P}<0.00000001$ was considered statistically significant.

Table 1: Criteria for the classification of the degree of affection of hepatocytes [13].

\begin{tabular}{|l|l|}
\hline Degree of affection & Criteria \\
\hline No affection & No morphological changes \\
\hline Mild affection & Swollen cells with pale cytoplasm (cloudy swelling) \\
\hline Moderate affection & Vaculated cytoplasm (Hdropic degeneration) \\
\hline Severe affection & Nuclear change with cytoplasmic affection (Necrosis) \\
\hline
\end{tabular}

For electron microscope study glutaraldehyde and formaline (3-1) were drippled on the remaining attached part of the liver and a small piece was excised and then trimmed under dissecting microscope in the presence of glutaraldehyde. The trimmed specimens were then fixed in glutaraldehyde at room temperature for 24 hours. After that they were washed overnight in several changes of $0.1 \mathrm{M}$ sodium phosphate buffer, $\mathrm{PH} 7.4$ at $4^{\circ} \mathrm{C}$ and then post-fixed in $2 \%$ osmium tetroxide in $0.1 \mathrm{M}$ sodium phosphate buffer, $\mathrm{PH} 7.4$ at room temperature. Specimens were then dehydrated in a graded series of cold ethanol and propylene oxide then embedded in spurr. Semithin sections $(1 \mu \mathrm{m})$, specimens were stained with toluidine blue were obtained for observation. Ultrathin sections $(60 \mathrm{~nm})$ were prepared using Reichert JUNG and stained with uranyl acetate and lead citrate and were examined with Philips 400 electron microscope.

\section{Results}

Generally, no changes were detected in mice in the control group; while loss of weight was detected in mice of the remaining group and bad odor were detected in mice of both DEHP and green tea/DEHP groups. Macroscopically; no changes were detected in liver of control group. In contrast, enlargement of the liver was detected in the remaining groups. Hematoxylin \& Eosin (H\&E) sections of liver of control animals showed normal polygonal hepatocytes with round nuclei and 
granular cytoplasm. Blood sinusoids and Kupffer cells were detected (Fig. 1). It was noticed that $(93.4 \%)$ of hepatocytes showed no affection, while no hepatocytes showed severe affection (Table.2). Some collagen fibers around blood sinusoids in sections of control animals stained with Masson's Trichrome were observed (Fig. 2). Glycogen granules in the cytoplasm of hepatocytes of control sections stained with PAS were detected (Fig. 3).

Fig. 1: Section in the liver of a control mouse showing trabeculae of hepatocytes separated by blood sinusoids (arrow head) and Kupffer cells (arrow).

\section{(H\&E X400) [13]}

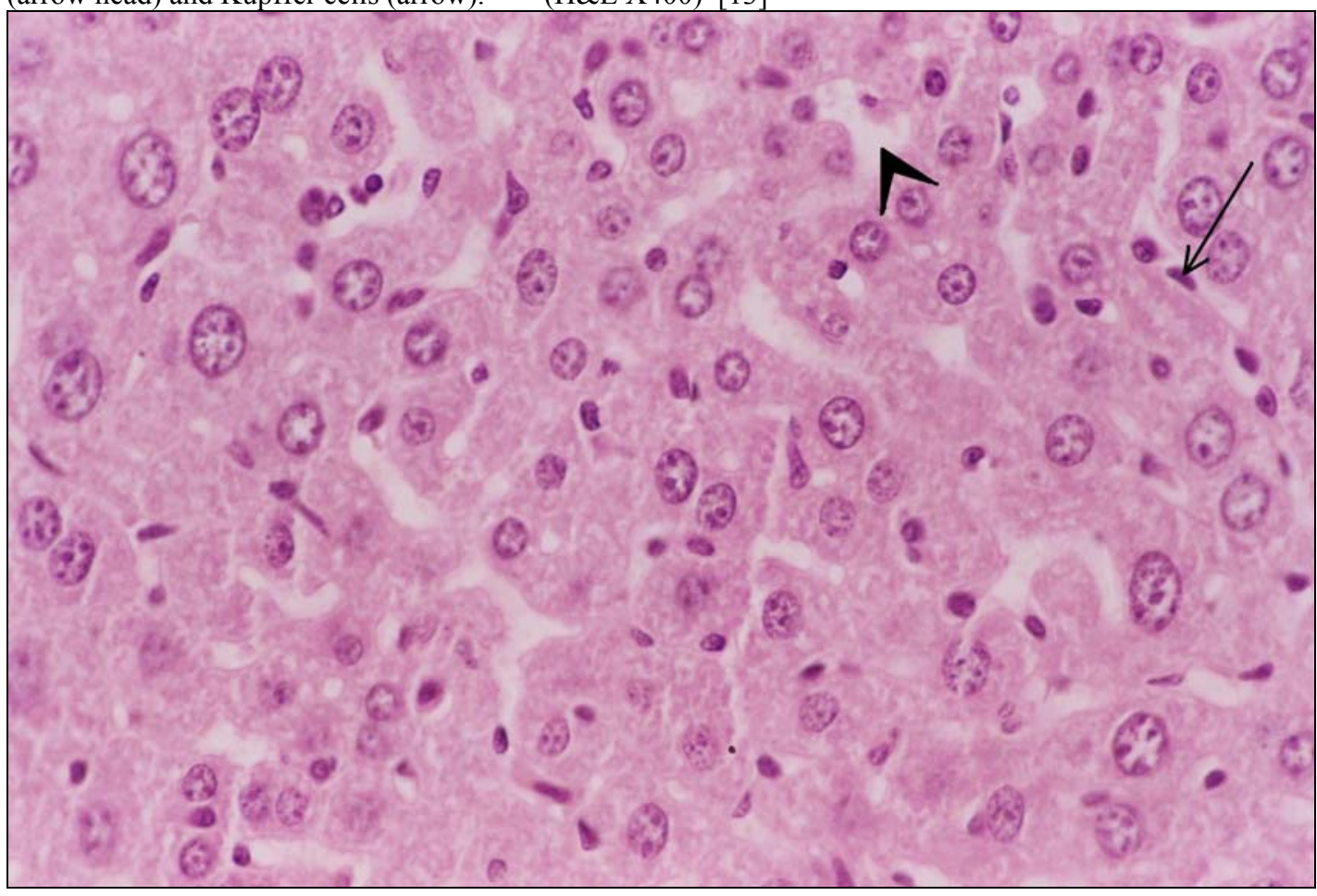

Table 2: The percentage of the different degrees of affection of hepatocytes in different groups.

\begin{tabular}{|l|c|c|c|c|c|c|c|c|}
\hline \multirow{3}{*}{ Degree of Affection } & \multicolumn{9}{c|}{ Study Groups } \\
\cline { 2 - 10 } & \multicolumn{2}{|c|}{ CI } & \multicolumn{2}{c|}{$\begin{array}{c}\text { Green tea } \\
\text { control* }\end{array}$} & \multicolumn{2}{c|}{ DEHP* } & \multicolumn{3}{c|}{ Green Tea* } \\
\cline { 2 - 10 } & No. & $\%$ & No. & $\%$ & No. & $\%$ & No. & $\%$ \\
\hline \multirow{2}{*}{ No Affection } & 168 & 93.4 & 8 & 4.4 & 3 & 1.7 & 2 & 1.1 \\
\hline Mild Affection & 8 & 4.4 & 10 & 5.6 & 5 & 2.8 & 4 & 2.2 \\
\hline Moderate Affection & 4 & 2.2 & 44 & 24.4 & 42 & 23.3 & 39 & 26.7 \\
\hline Severe Affection & 0 & 0.0 & 118 & 65.6 & 130 & 72.2 & 135 & 70.0 \\
\hline Total & 180 & 100 & 180 & 100 & 180 & 100 & 180 & 100 \\
\hline
\end{tabular}

* $\mathrm{P}<0.00000001$ when compared with CI group

$\mathrm{CI} \& \mathrm{CII}$

$\mathrm{CI} \& \mathrm{DEPH}$

CI \& green tea

CII \& DEPH

CII \& Green tea

DEPH \& Green tea

$$
\begin{array}{ccc}
\text { chi-square }=297.01 & \mathrm{P}<0.00000001 \\
\text { chi-square }=321.29 & \mathrm{P}<0.00000001 \\
\text { chi-square }=326.92 & \mathrm{P}<0.00000001 \\
\text { chi-square }=4.57 & \mathrm{P}=0.21 & \text { Not significant } \\
\text { chi-square }=7.61 & \mathrm{P}=0.06 & \text { Not significant } \\
\text { chi-square }=0.52 & \mathrm{P}=0.91 & \text { Not significant }
\end{array}
$$


Fig. 2: Section in the liver of a control mouse showing some collagen fibers around blood sinusoids. (Masson's Trichrom X400)

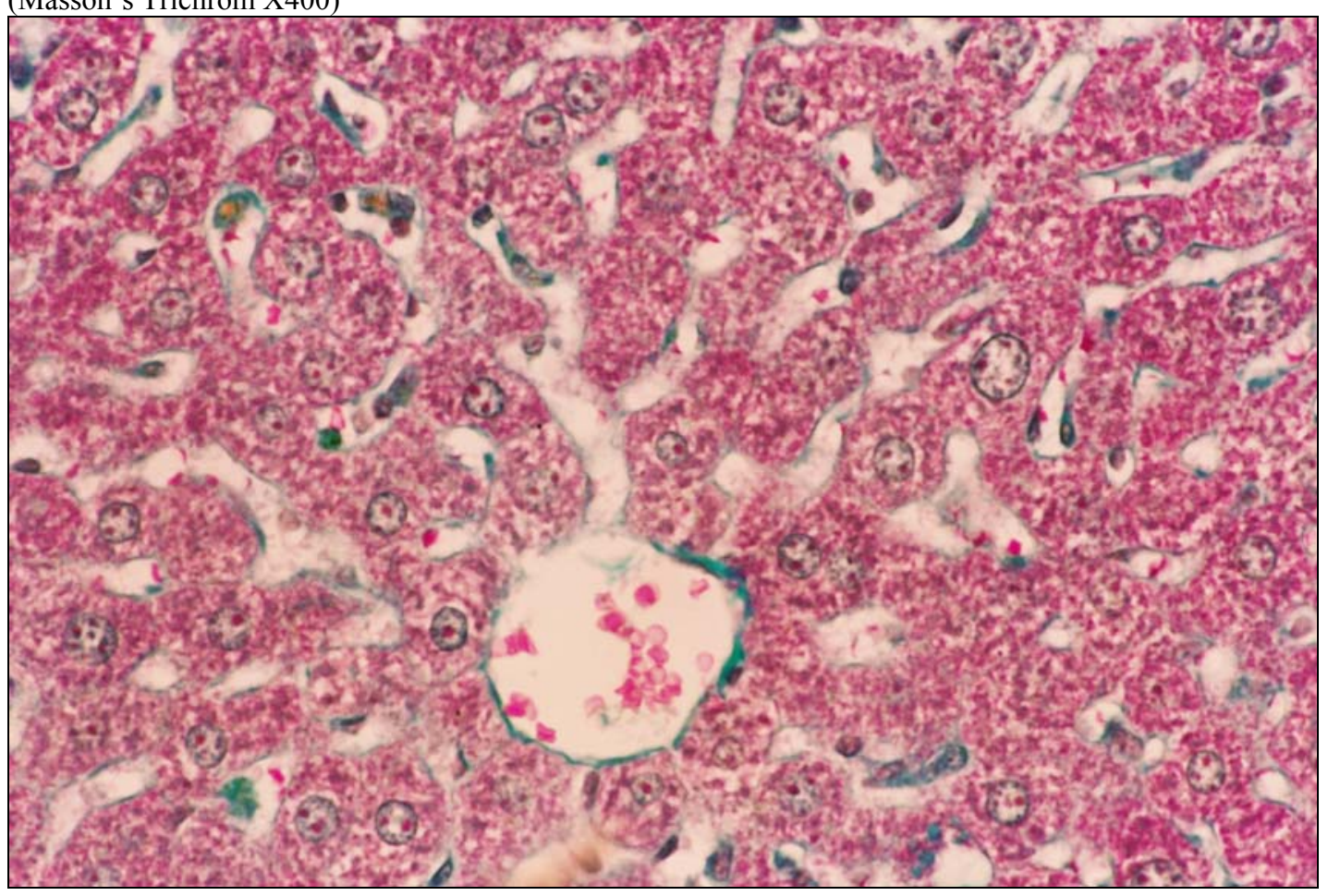

Fig. 3: Section in the liver of a control mouse showing glycogen granules in the cytoplasm of hepatocytes. (PAS X400)

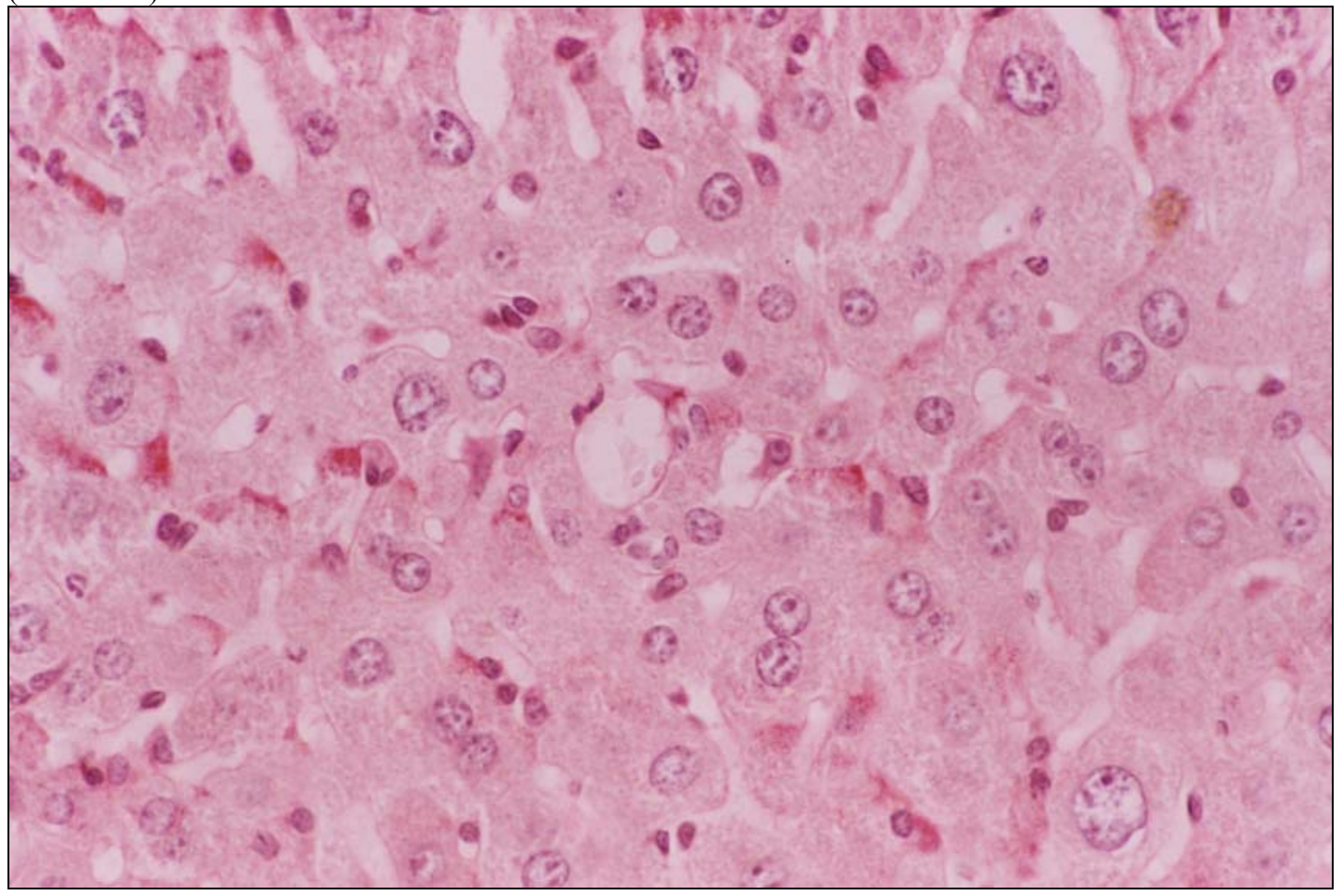


Fig. 4: Section in the liver of a green tea control mouse showing cellular necrosis in most hepatocytes in the form of vaculated cytoplasm (arrow) with pyknotic (p), karyorrhetic (k) or karyolytic (y) nuclei. $(\mathrm{H} \& \mathrm{E} X 400)$

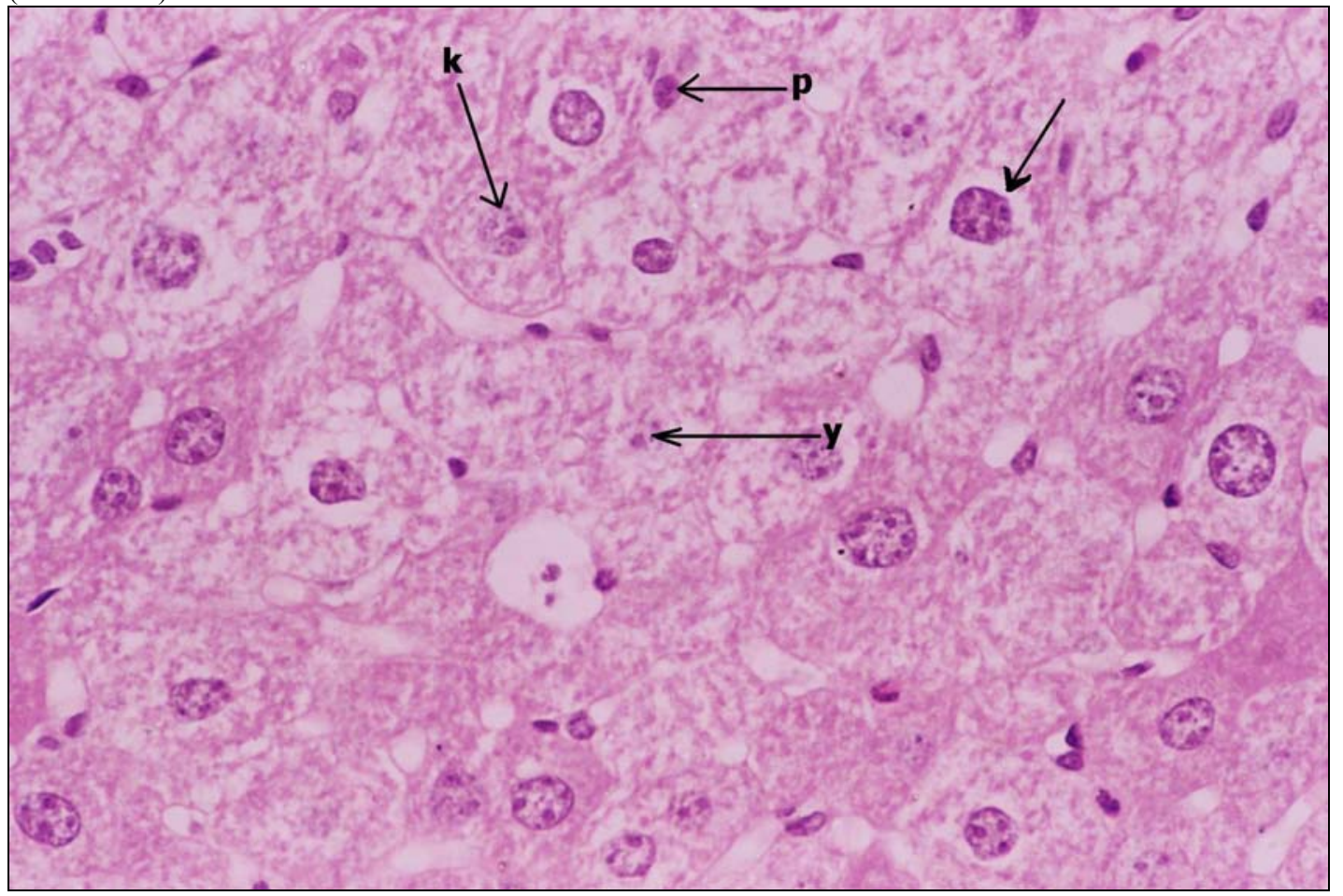

Fig. 5: Section in the liver of a green tea control mouse showing moderate increase in the amount of collagen fibers around blood sinusoids. (Masson's Trichrom X400)

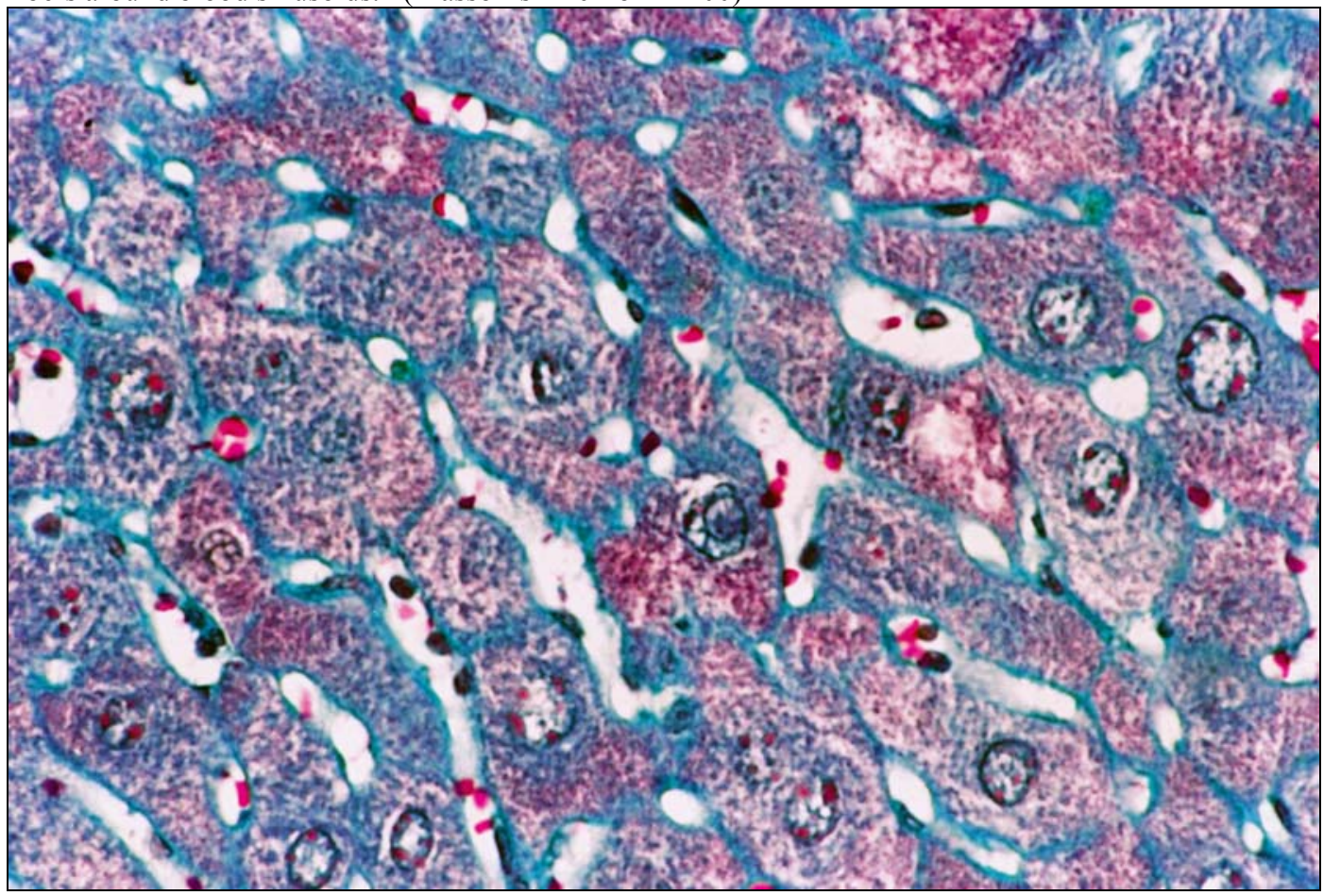

Sections of liver of animals of green tea control group showed severe degenerative changes in the form of hydropic degeneration with enlarged nuclei in most hepatocytes, Table (2). Cloudy swelling 
and necrosis in the form of nuclear pyknosis, karyorrexis or karyolysis with vaculated or darkly eosinophilic cytoplasm were detected also in some hepatocytes (Fig. 4). Hepatocytes in green tea control group showed $(65.6 \%) \&(24 \%)$ severe and moderate affection, only $(4.4 \%)$ of hepatocytes showed no affection (Table. 2). Moderate increase in collagen fibers around blood sinusoids in sections of green tea control animals stained with Masson's Trichrome was observed (Fig. 5). Most hepatocytes of green tea control sections stained with PAS showed moderate decrease in glycogen granules (Fig. 6).

Fig. 6: Section in the liver of a green tea control mouse showing moderate decrease in the amount of glycogen of most of hepatocytes. (PAS X400)

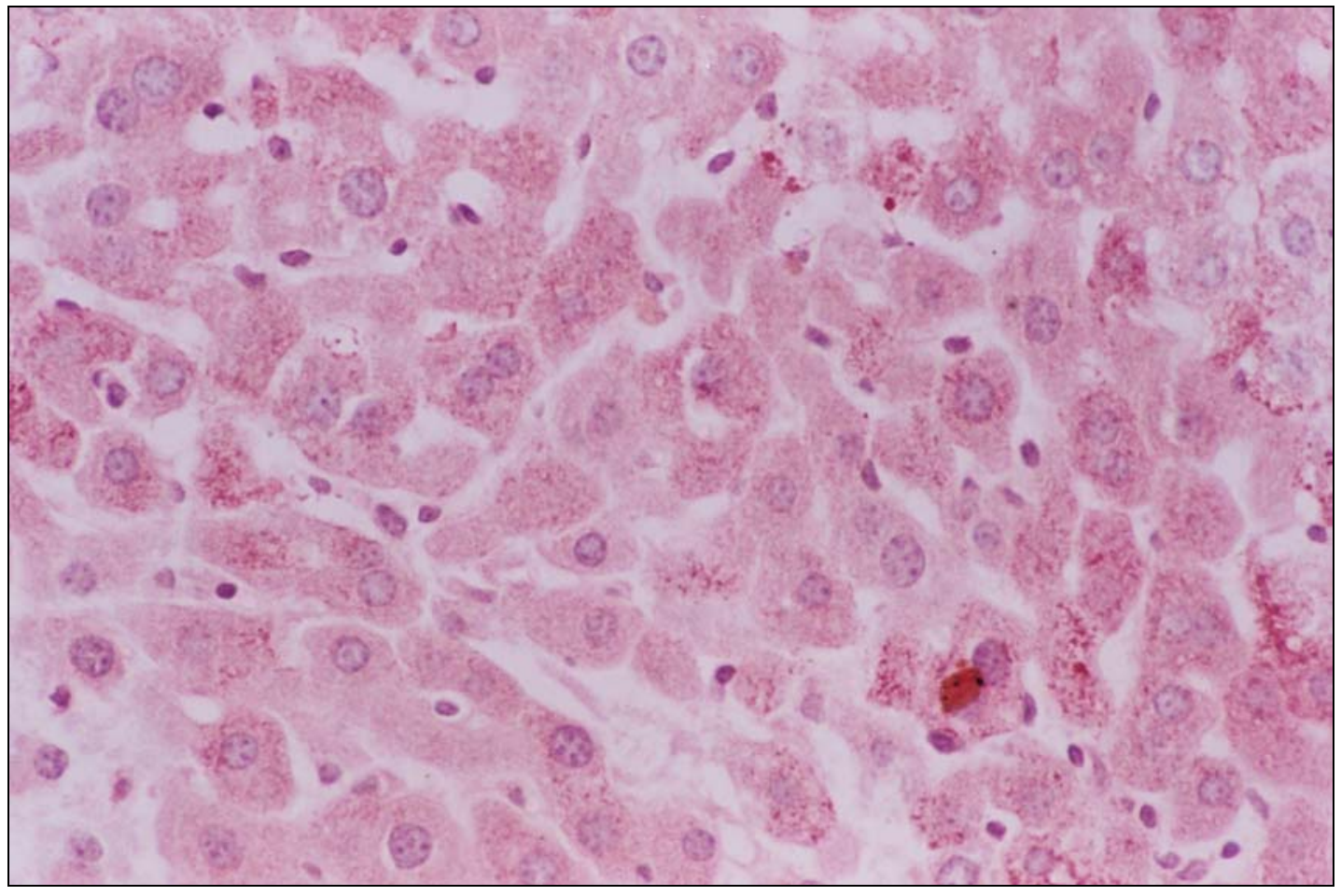

Animals DEHP group showed severe degenerative and necrotic changes in most hepatocytes. Necrosis detectable in the form vaculated cytoplasm with pyknotic, karyorrhetic or karyolytic nuclei. Some hepatocytes showed nuclei with chromatin margination and dark eosinophilic cytoplasm (Fig. 7). Dilatation of blood sinusoids and central vein were detected. About three-fourth of hepatocytes $(72.2 \%)$ in DEHP group showed severe affection and $(26.7 \%)$ of hepatocytes showed moderate affection while only $(1.7 \%)$ of hepaycytes in this group showed no affection (Table.2). Marked increase in collagen fibers around blood sinusoids and around portal tracts in sections of DEHP animals stained with Masson's Trichrome were detected (Fig. 8). PAS- stained sections showed that most hepatocytes were depleted of glycogen content and often showed vaculation of their cytoplasm (Fig. 9). Animals that green tea/DEHP group showed similar changes to those of the group received DEHP in addition to heavy mononuclear cellular infiltration and dilatation in many portal tracts and interlobular septa (Fig. 10\& 11). Among green tea/DEHP group $(70.0 \%) \&(26.7 \%)$ of hepatocytes showed severe and moderate affection, only $(1.1 \%)$ of hepatocytes showed no affection. (Table.2). Statistical analysis of the results when compared to control group, there was a significant increase in the severity of hepatocytes affection in green tea group (chi-square $=297.01$ $\mathrm{P}<0.00000001)$, DEHP (chi-square $=321.29$ $\mathrm{P}<0.00000001$ ) and green tea/DEHP group (chisquare $=326.92 \quad \mathrm{P}<0.00000001)$. When comparing green tea control group, DEHP \&green tea/DEHPgrouyps with each other there was no significant difference was noticed (Table.2). Moderate increase in collagen fibers around blood sinusoids in sections of green tea/DEHP animals stained with Masson's Trichrome was detected (Fig. 12). PAS- stained sections showed that most hepatocytes were depleted of glycogen content (Fig. 13). 


\section{Electron microscopy}

With transmission electron microscope, the cytoplasm of hepatocytes of control I animals were packed with mitochondria. Rough endoplasmic reticulium was mainly arranged besides the mitochondria.

Smooth endoplasmic reticulium were abundant. Lysosomes of all kinds were also present. Golgi stacks were scattered in the cytoplasm. Many microbodies were seen. Lipid and glycogen granules were also detected. The nucleus of hepatocytes was rounded (Fig. 14). Chromatin was arranged as peripheral chromatin, chromatin islands and nucleolus associated chromatin. Blood sinusoids were lined by flat endothelial cells as well as Kupffer cells. The space of Disse, found between the hepatocytes and the wall of the blood sinusoids, contained innumerable microvilli projecting from the surface of hepatocytes (Fig.14).

Fig. 7: Section in the liver of a DEHP mouse showing cellular necrosis in the form of vaculated cytoplasm with karyorrhetic (k) or karyolytic (y) nuclei in many hepatocytes. Eosinophilic cytoplasm with dark nuclei in few hepatocytes (EP) also seen. (H\&E X400)

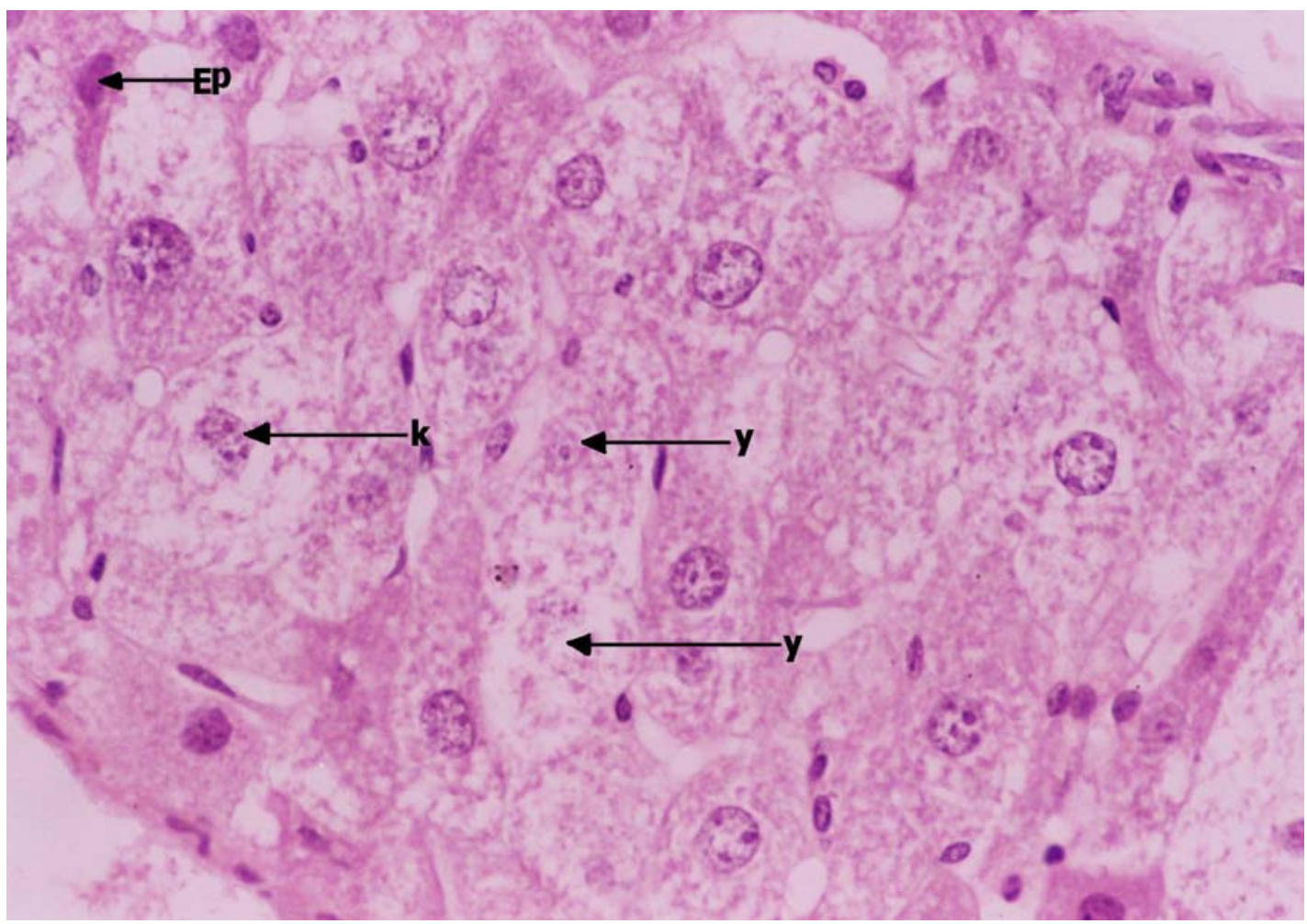


Fig. 8: Section in the liver of a DEHP mouse showing marked increase in the amount of collagen fibers around blood sinusoids and portal tract. (Masson's Trichrom X400)

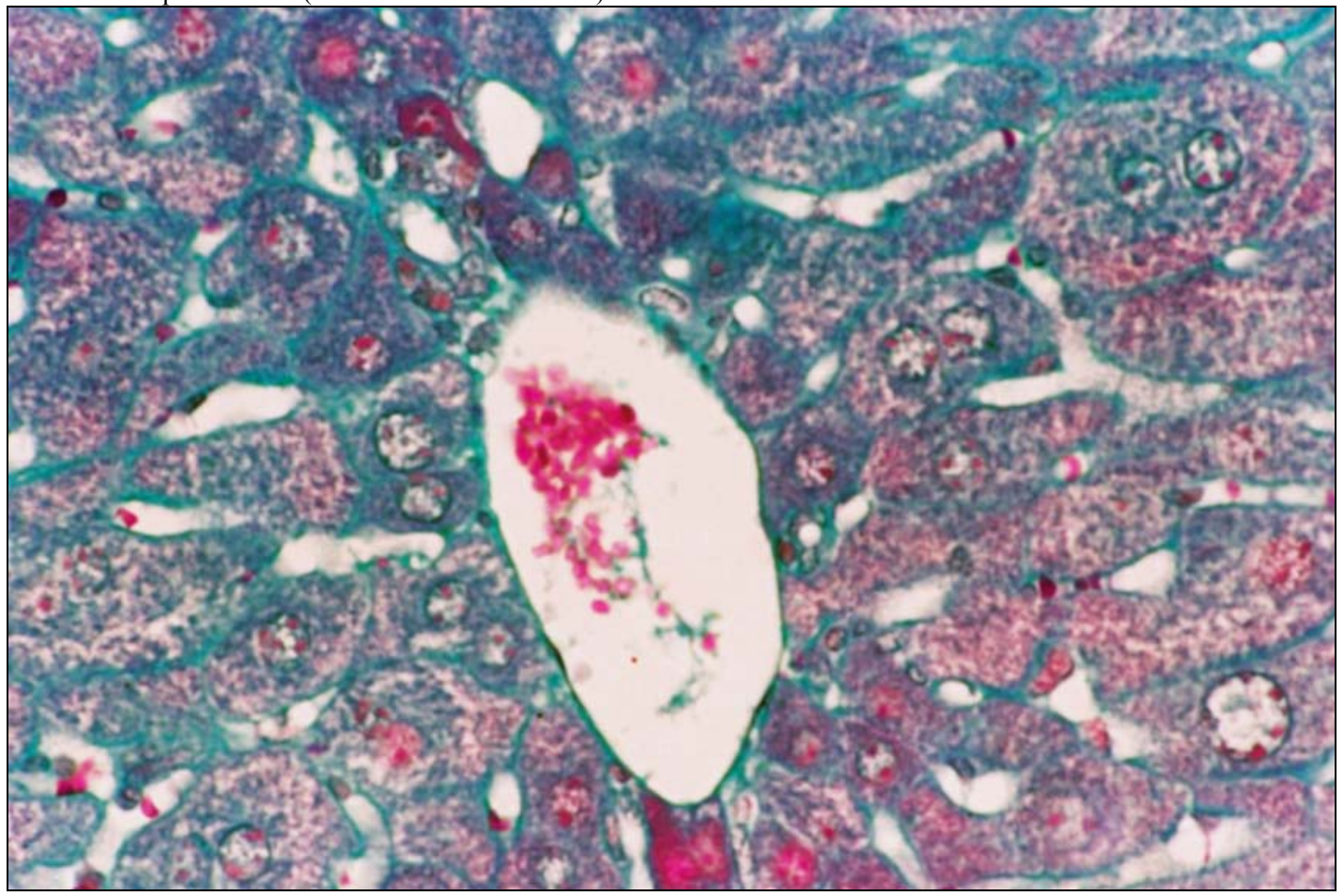

Fig. 9: Section in the liver of a DEHP mouse showing marked decrease in glycogen content of most of hepatocytes. (PAS X400)

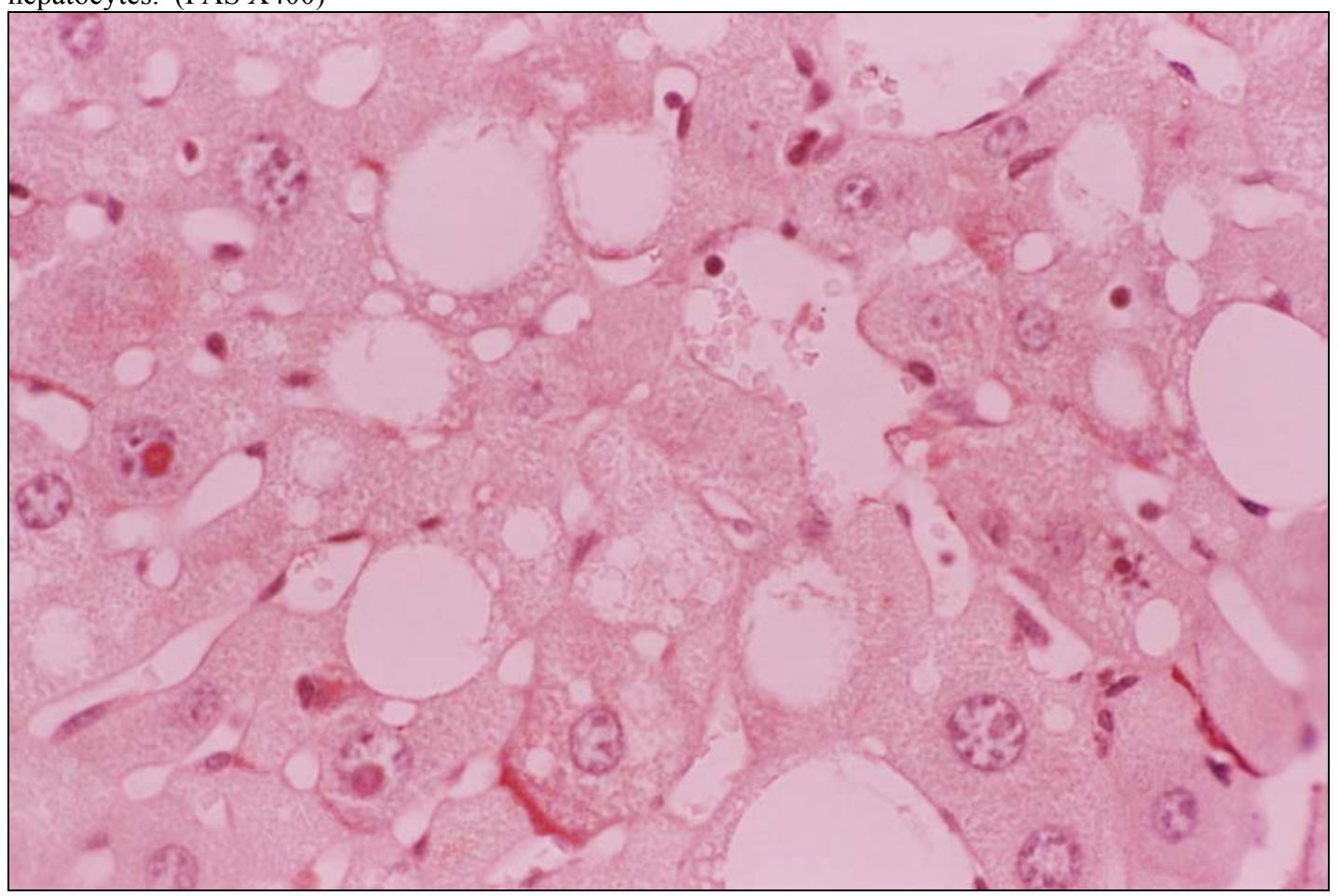


Fig. 10: Section in the liver of a green tea/DEHP mouse showing dilatation and mild mononuclear cellular infiltration in the portal tract. (H\&E X100)

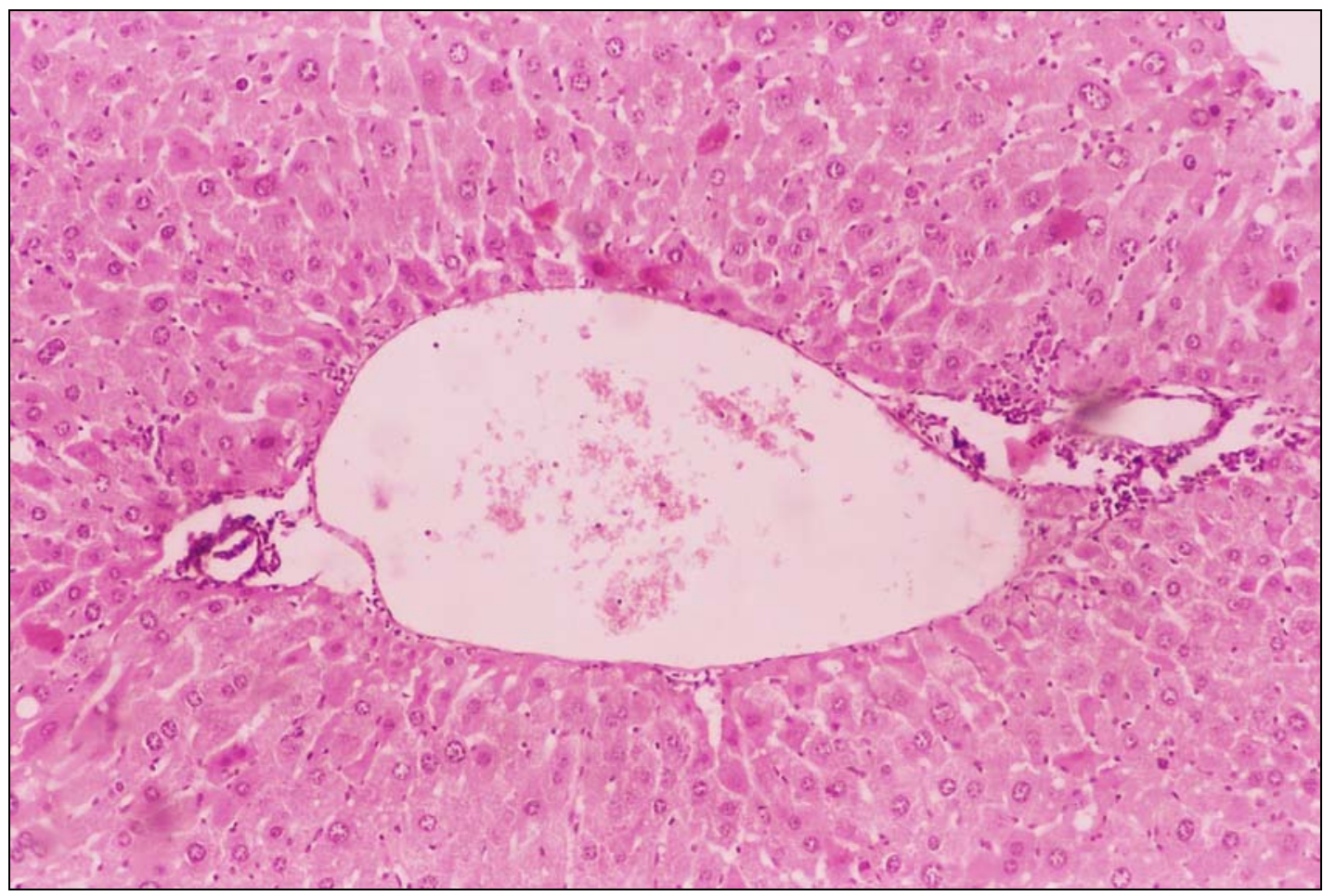

Fig. 11: Section in the liver of a green tea/DEHP mouse showing and heavy mononuclear cellular infiltration. Necrosis appears in most hepatocytes. (H\&E X400)

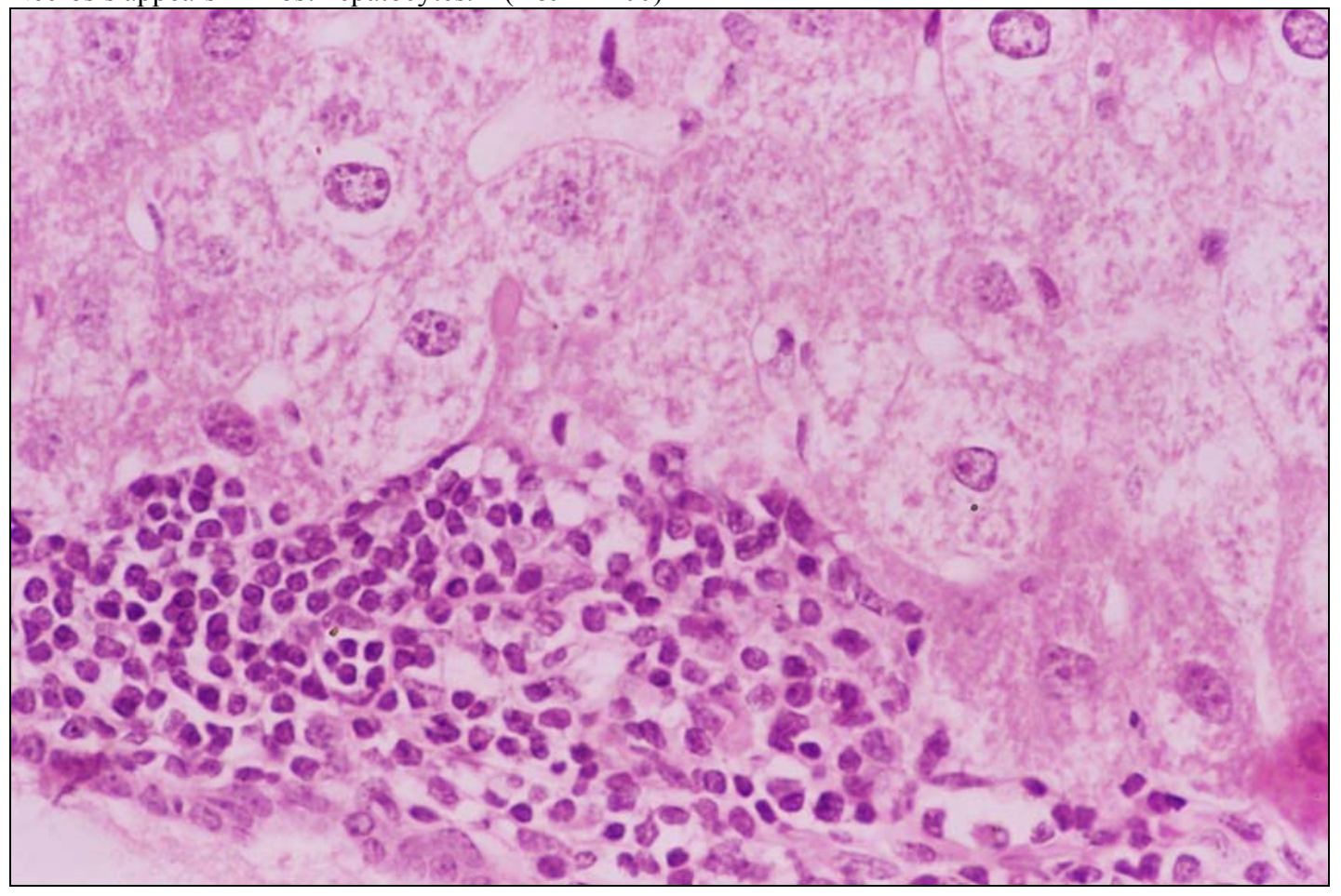


Fig. 12: Section in the liver of a green teas/ DEHP mouse showing marked increase in the amount of collagen fibers around blood sinusoids. (Masson's Trichrom X400)

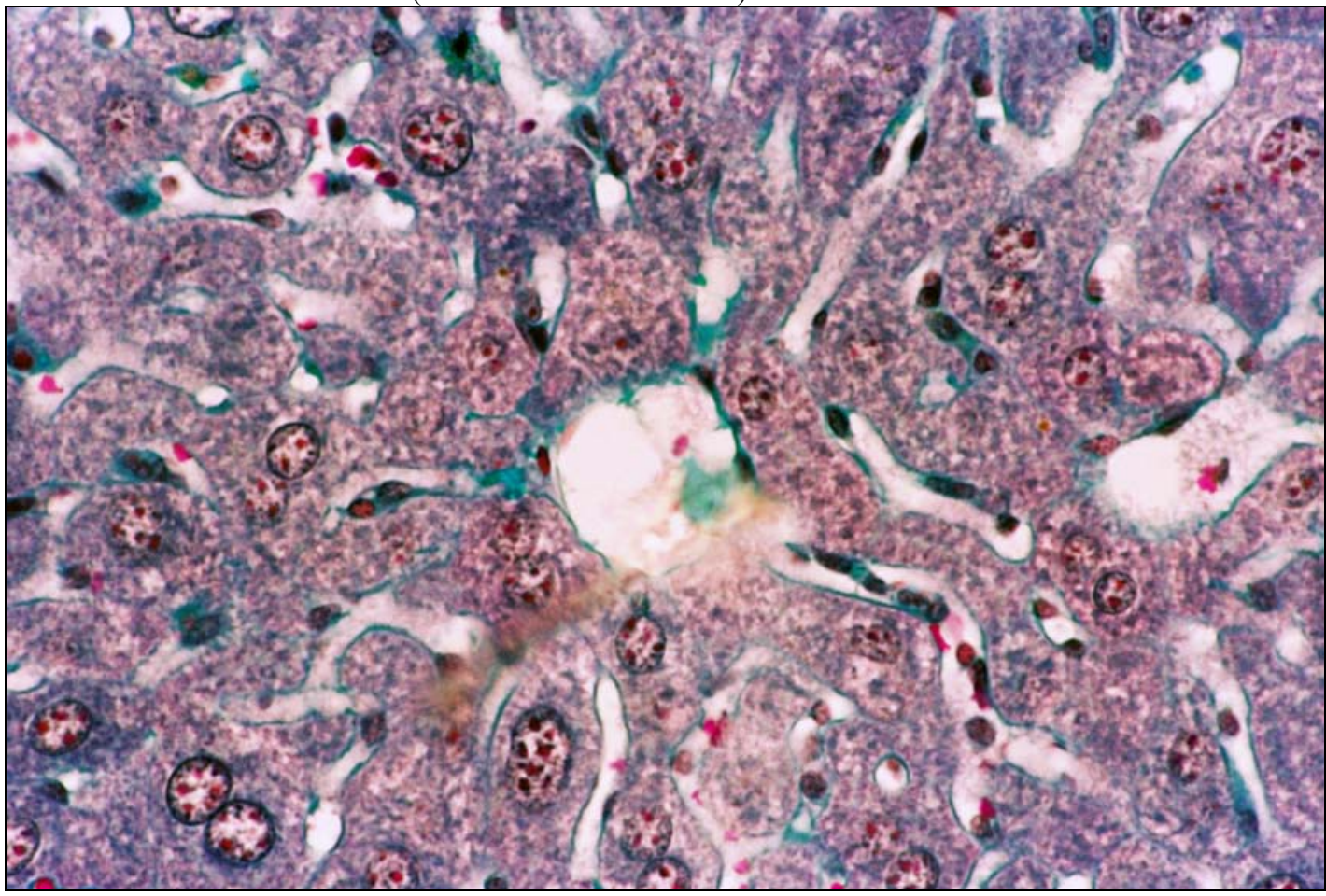

Fig. 13: Section in the liver of a green tea/DEHP mouse showing marked decrease in glycogen content of most of hepatocytes. (PAS X400)

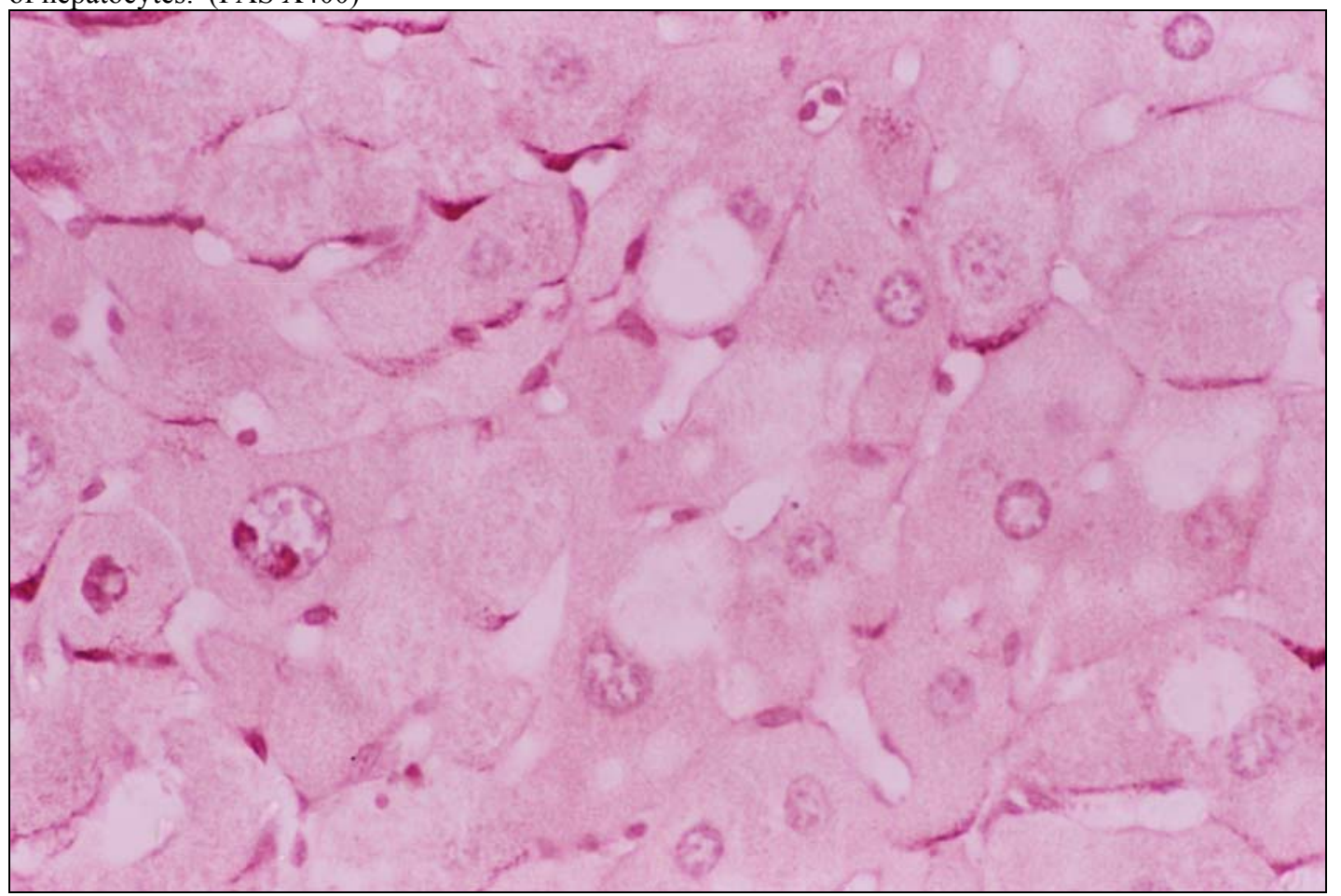


Fig.14: Electron micrograph of hepatocyte of a control mouse showing nucleus $(\mathrm{N})$, many mitochondria (M), rough endoplasmic reticulium $(\mathrm{R})$, Golgi apparatus $(\mathrm{G})$, many lysosomes $(\mathrm{L})$, glycogen granules $(\mathrm{g})$ and lipid globules $(*)$. Numerous microvilli $(\mathrm{m})$ extending from the sinusoidal surface of hepatocytes also shown. (X 8280).

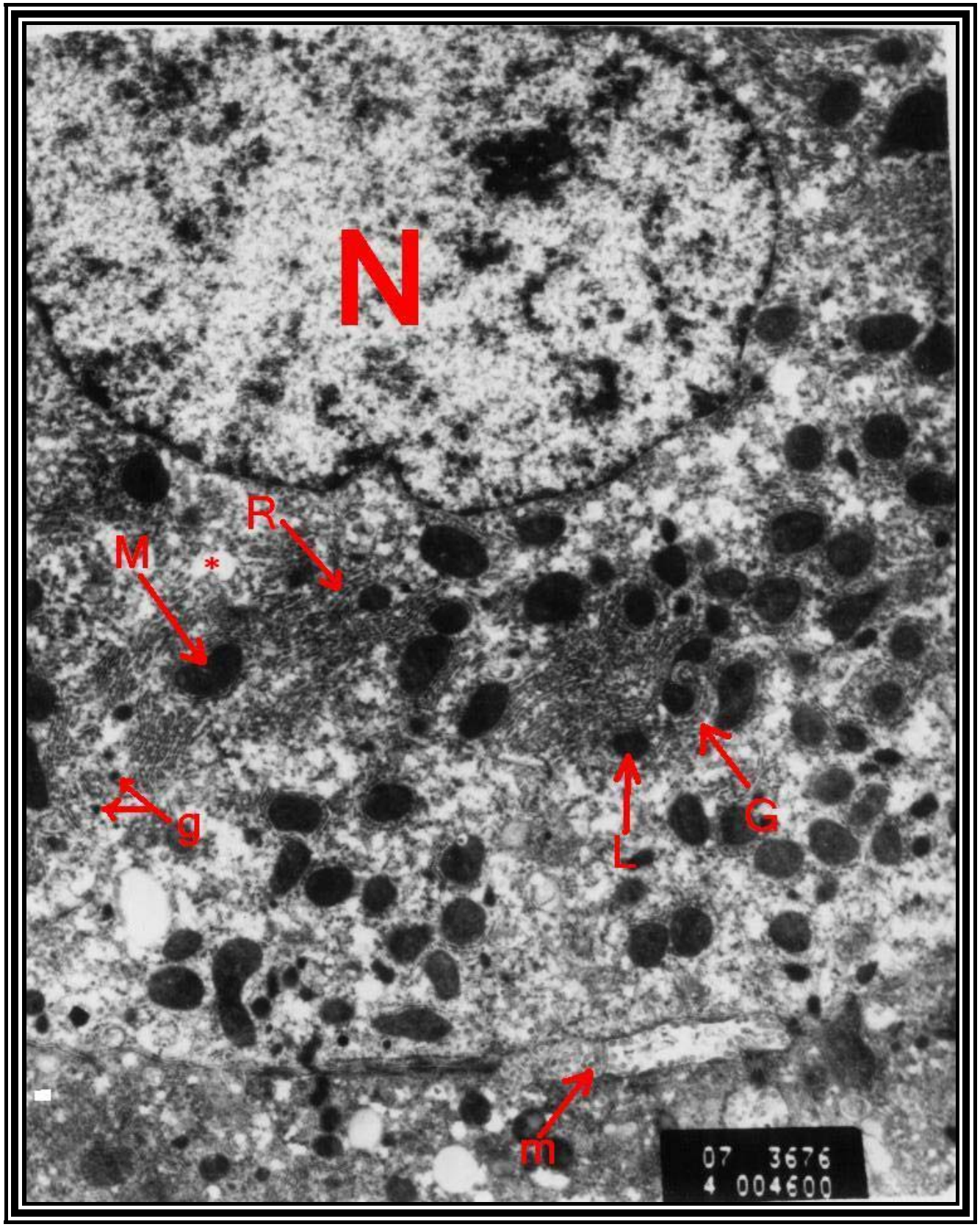

Transmission electron microscopic examination of hepatocytes of animals, which received green tea tablets, showed vacules in the cytoplasm and poorly identifiable organelles (Figs.15 \& 16). Explained by degeneration of all cytoplasmic organelles
(Figs.15 \& 16). Nucleus in some hepatocytes showed chromatin condensation (Fig.15). Chromatin fragmentation also observed in some hepatocytes (Fig.16). 
Fig. 15: Electron micrograph of hepatocyte of a green tea mouse showing cytoplasmic vacules (V) degenerated cytoplasmic organelles. Condensation of nuclear chromatin (c) and degenerated microvilli (arrow) also observed. (X 14400).

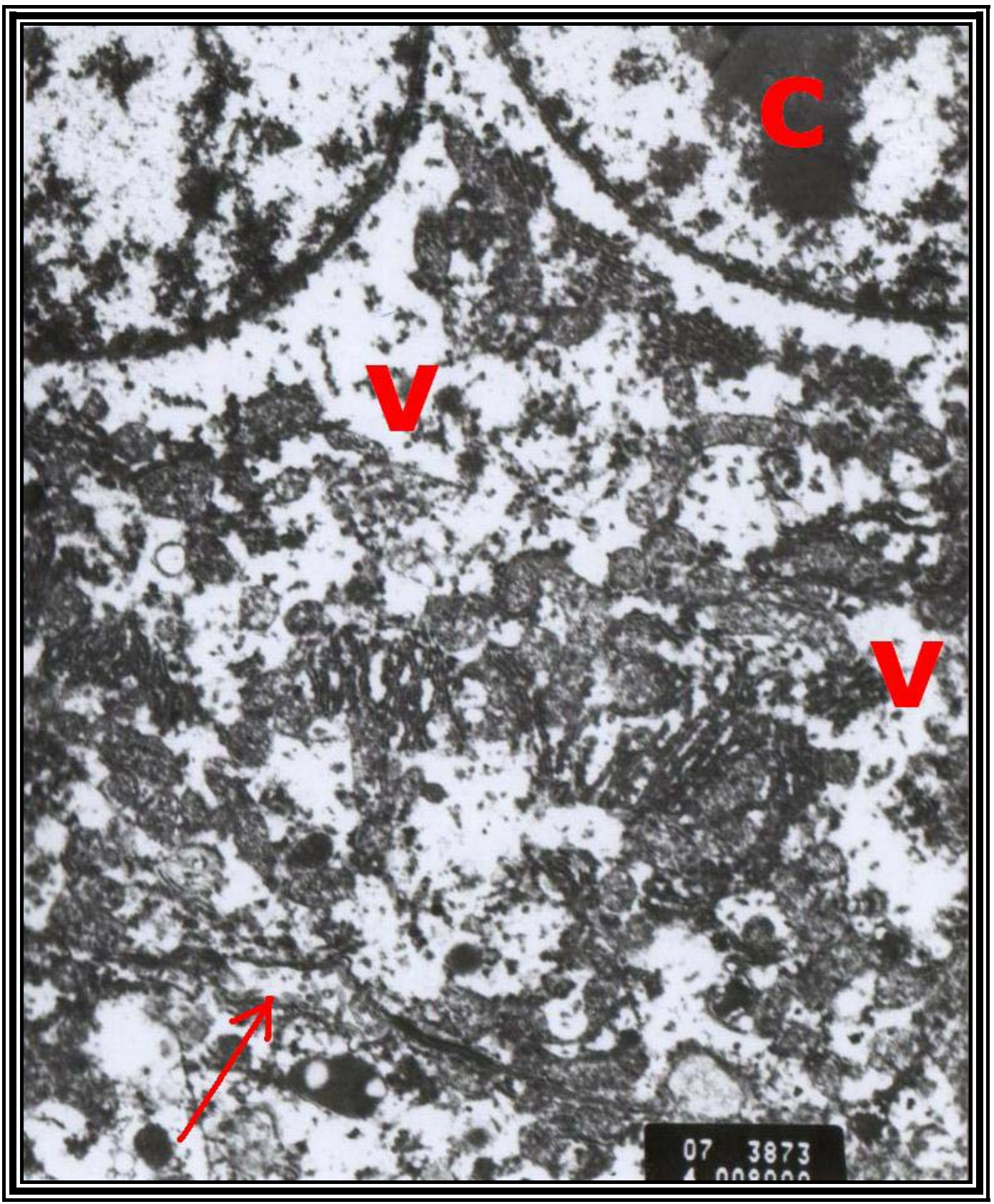


Fig. 16: Electron micrograph of two adjacent hepatocytes of a green tea mouse showing cytoplasmic vacules $(\mathrm{V})$, degenerated cytoplasmic organelles and disrupted cell membrane $(\mathrm{C})$. Fragmentation of nuclear chromatin also seen (f). (X 10800).

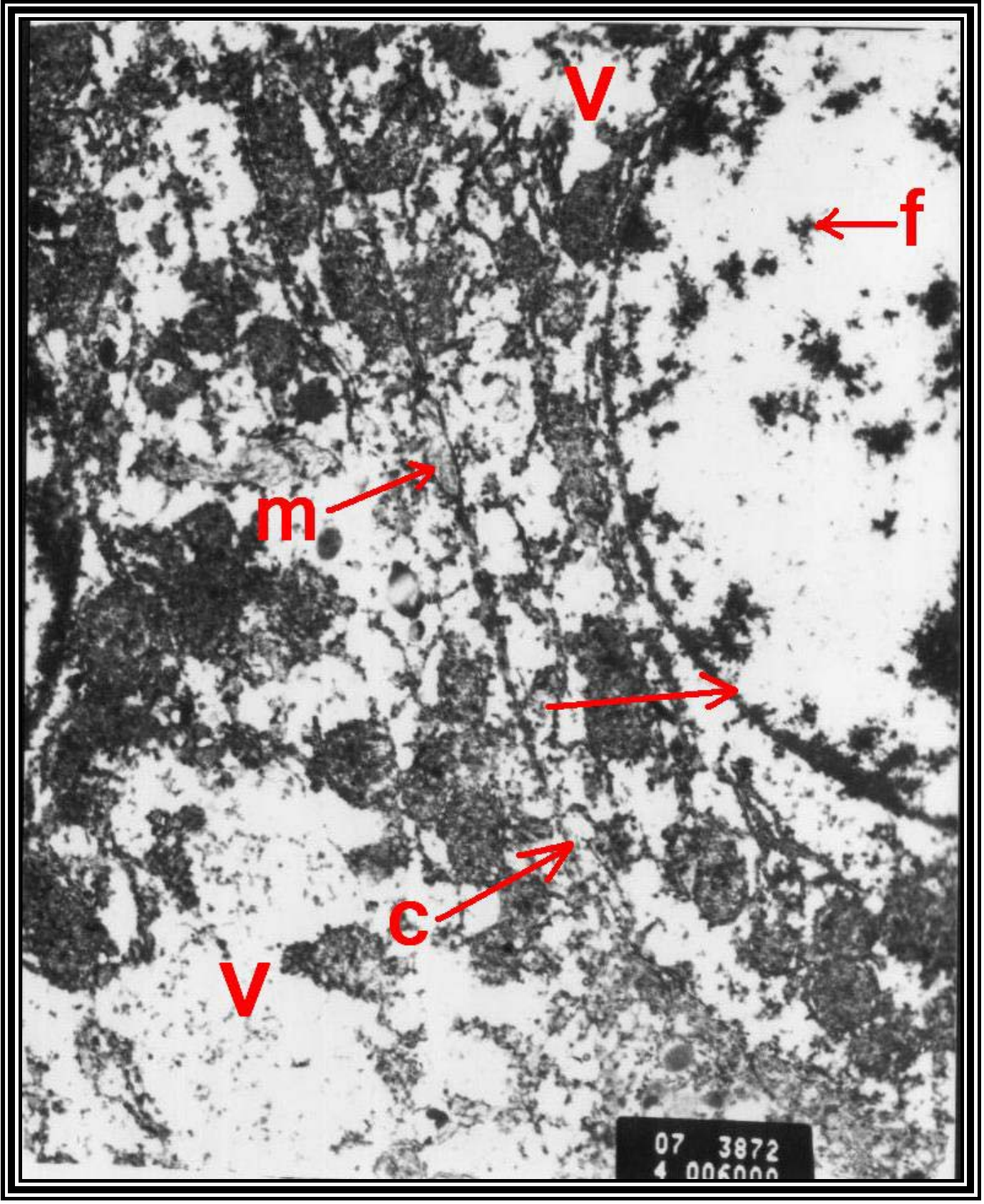

Transmission electron microscopic examination of hepatocytes of animals, which received DEHP, showed marked increase in lipid globules deposition and enlarged and degenerated mitochondria. Dilatation and destruction of both rER cisternae and Golgi apparatus with loss of their arrangement were seen. Depletion of glycogen granules and increase number of lysosomes, lipid filled lysosomes and perxisones also were observed (Fig.17). The nucleus in many hepatocytes showed enlargement, chromatin fragmentation, disrupted nuclear membrane and lipid globules deposition (Fig.18). 
Fig. 17: Electron micrograph of hepatocyte of a DEHP mouse showing marked increase in lipid globules (L) deposition, increase in lysosomes $(*)$ \& perxisomes $(\mathrm{P})$, dilatation of rER cisternae $(\mathrm{R})$ \& Golgi apparatus cisternae (G) and depletion of glycogen granules. Dilatation of smooth endoplasmic reticulium (S) also observed. (X 14400).

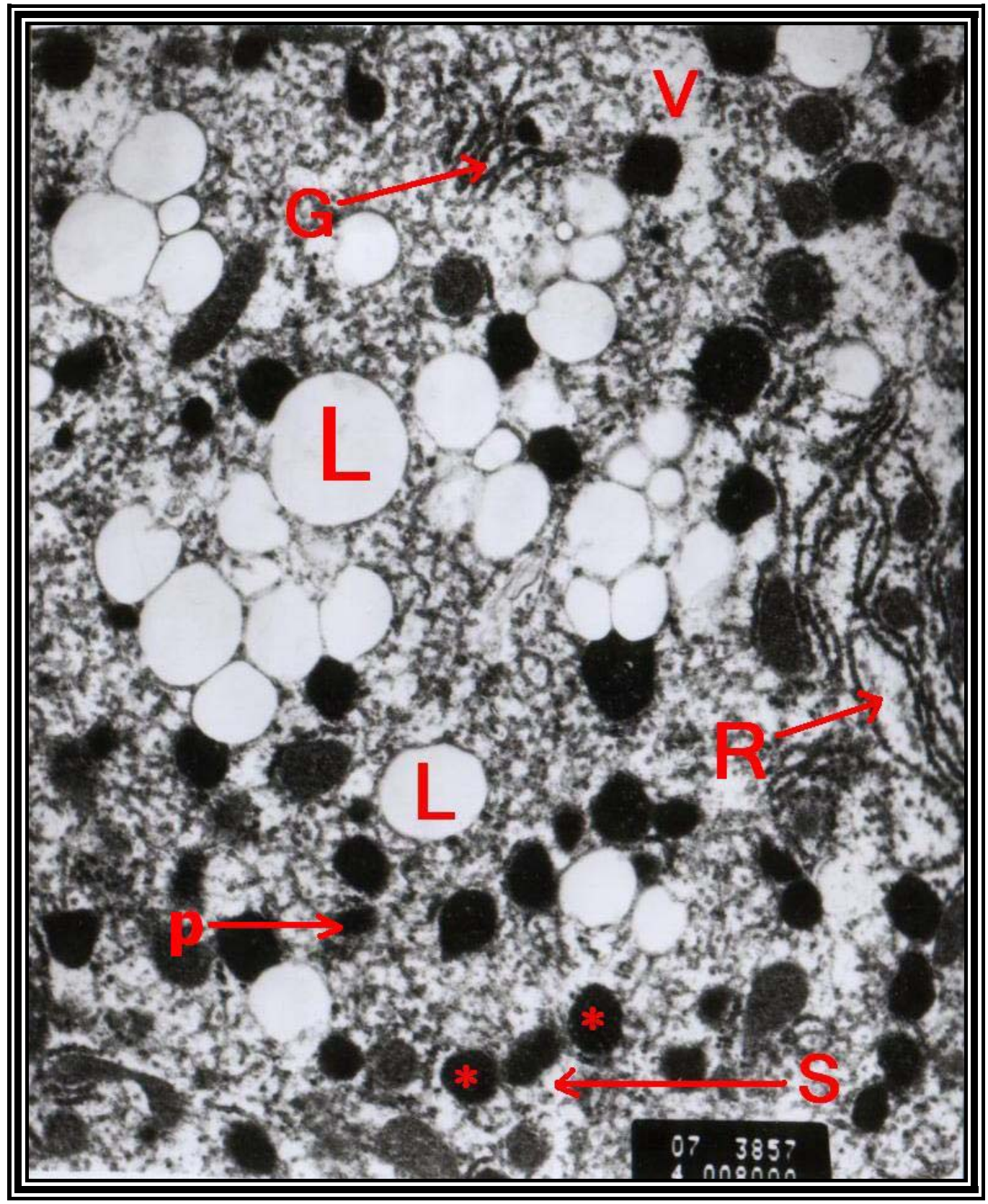


Fig. 18: Electron micrograph of hepatocyte of a DEHP mouse showing dilated rER cisternae (R) and lipid filled lysosomes (I). Enlargement of the nucleus, fragmentation of nuclear chromatin and deposition of fat globules within the nucleolus (L) also seen. (X 10800).

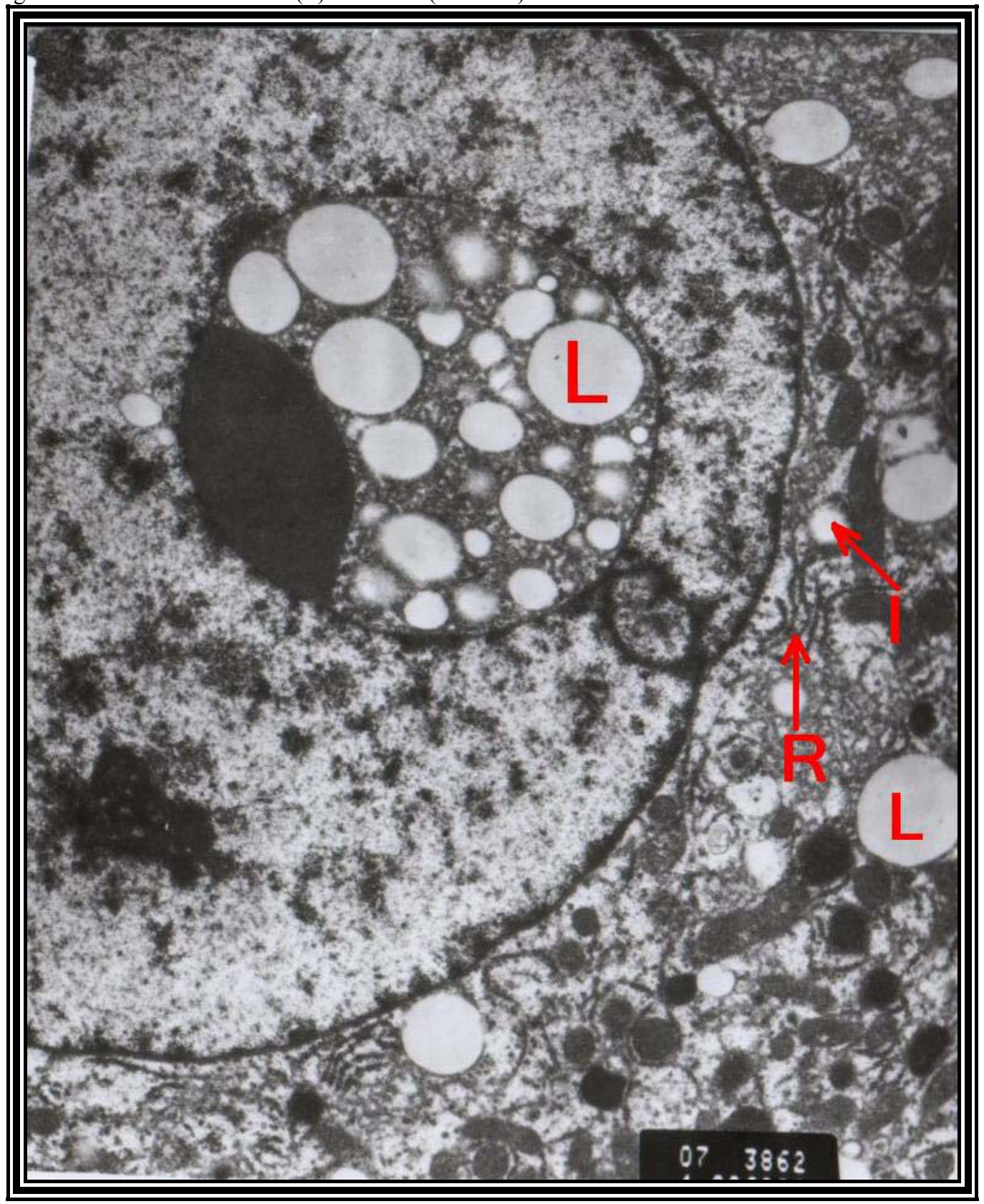

Transmission electron microscopic examination of hepatocytes of animals which received green tea/DEHP showed ultrastructural changes similar to

those detected in DEHP group except marked increase in cytoplasmic vaculation and marked decrease in lipid globule deposition (Fig. 19). 
Fig.19: Electron micrograph of hepatocyte of a green tea/ DEHP mouse showing cytoplasmic vacules (V), degenerated mitochondria $(\mathrm{M})$, degenerated $\mathrm{rER}(\mathrm{R})$, dilated rER cisternae $\left(\mathrm{R}^{*}\right)$ and decrease in lipid globules deposition (L). Fragmentation of nuclear chromatin (F) and disrupted nuclear membrane $\left(^{*}\right)$ also seen. (X 14400).

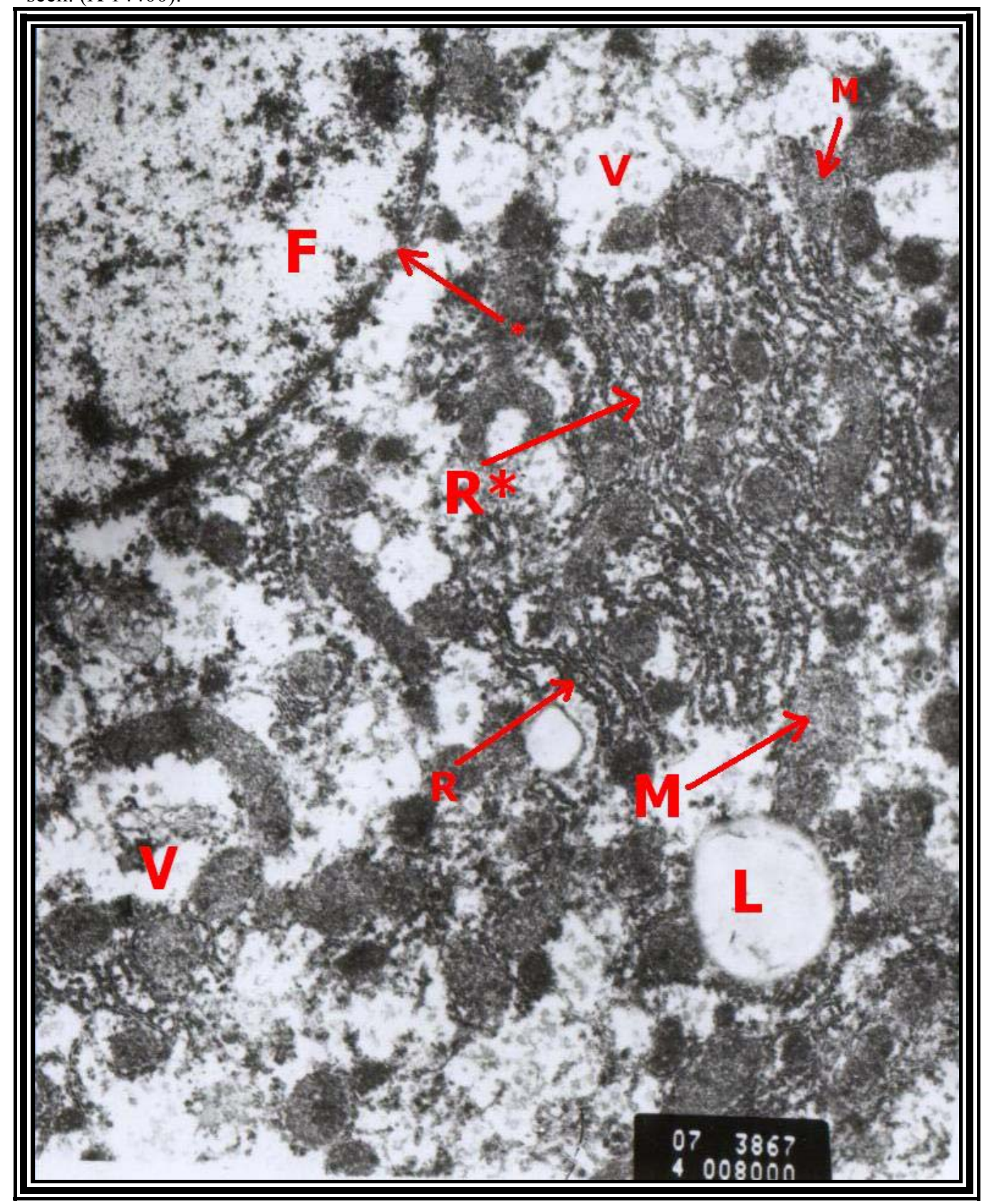

\section{Discussion}

Studies indicated that oral exposure to DEHP resulted in toxic effects in human and rodent species. Oral studies in mice and rat have established that the main target of DEHP toxicity is the liver [6]. There have been no studies of specific techniques for reducing DEHP body burden [2]. The present study was undertaken to determine the postulated protective role of green tea against DEHP liver toxicity in mice. In the beginning of the study the mice were distributed in four groups; control group, group receiving green tea, group receiving three successive doses of DEHP, and the last group receiving green tea and The group receiving DEHP showed DEHP. hepatic cell hyperplasia; this is due to rapid cell 
division, which appears to be the initial physiological response to DEHP exposure $[3,4]$ explained this hyperplasia by the relative increase in DNA synthesis following DEHP administration. Increased number of lysosomes and mitochondria were observed in our study, this was also detected by Thomas \& Thomas [5] who claimed a definite increase in mitochondria and lysosomes, which was explained by the increase in DNA synthesis. The group receiving DEHP also expressed marked fatty infiltration in hepatic cells, this was also shown by Price et al. [8] who claimed the presence of tatty infiltration in the hatocytes and fat deposits in the periportal area of rats receiving oral DEHP.

Studies done by David et al [6] ${ }^{\text {indicated }}$ that the activities of the enzymes responsible for fatty acid catabolism (palmitoyl-CoA oxidase, enoyl-CoA hydratase, carnitine acyltransferase and aglycerophosphate dehydrogenase) were increased in rodents after exposure to DEHP by factors as great as $150 \%$. Also Bette [1] indicated that administration of DEHP for three days to rats resulted in significant increase in the phosphatidylcholine and phosphatidylethanolanine, leading to increase in total liver lipoid content and total phospholipid. Since green tea products are widely used as dietary supplements, and besides that several reports indicated the beneficial health effects of green tea as an antioxidative, antiinflammatory, and anticarcinogenic compound [14]; In the present study we are interested in using green tea as a protective agent against hepatotoxicity by DEHP. The results obtained from the group receiving green tea was contradictory to our expectations, as it showed complete destruction of the cytoplasmic organelles, vaculation in cytoplasm, destruction of cell membrane and marked destruction of mircrovilli of blood sinusoids. On nuclear level marked chromatin fragmentation and condensation, destruction of the nuclear membrane deposition of fat globules within the nucleolus. Fortunately our results were confirmed later by a study done by Smidth et al [15] who concluded that green tea extracts can exert acute toxicity in rat liver cells and (Epigallocatechin-3-gallate) seems to be the key constituent responsible for these effects and this occurred directly by the plant derivatives or after its metabolic activation. This was also in accordance with the work done by Pitter and Ernest [16], who reported that constituents of plantderived drugs might damage rat hepatocytes. The group of mice receiving both DEHP and green tea showed a reduction in the toxic effects of DEHP represented by decreased fatty infiltration in the hepatocytes "which was the main toxic effect detected by DEHP exposure" compared with the group receiving DEHP only. On the other hand the damage found in the group receiving green tea was still detected in the group receiving both DEHP and green tea but to a lesser extent. It seems that the administration of both drugs together may affects the rate of absorption and the effectiveness of each one. From the present work we concluded that green tea did not influence positively in improving the damage caused by DEHP in rat hepatocytes. We were also surprised by the findings, which were detected on electron microscopic level in hepatocytes of mice receiving green tea. Further work including studies concerned with the green tea formula and its effects on the liver will be warranted; and also studies including human

hepatocytes will increase the validity of the work.

\section{References}

1. Bette H. Alert on phthalates. Chemicals and Engineering Government and policy. 2000; 78:1-4

2. Enviro Tools Fact sheet adapted from ATSDR: (DEHP) di (2-ethylhexyl) phthalate. Enviro Tools, September. 2002

3. David RM, Moore MR, Cifone MA, Finney DC and Guest D. Chronic peroxisome proliferation and hepatomegaly associated with the hepatocellular tumorigenesis of di (2ethylhexyl)phthalate and the effects of recovery. Toxicological Sciences. 1999; 50:195-205.

4. Lake BG, Kozlen SL, Evans JG, Gray TJ, Young PJ and Gangoli SD. Effect of prolonged administration of clofibric acid and di(2-ethylhexyl)phthalate on hepatic enzyme activities and lipid peroxidation in the rat. Toxicology. 1987; 44: 213-28.

5. Thomas JA and Thomas MJ. Biological effects of di(2-ethylhexyl)phthalate and other phthalic acid esters. Critical Reviews in Toxicology. 1984; 13: 283-317.

6. David RM, Moore MR, Finney DC and Guest D. Chronic toxicity of $\operatorname{di}(2-$ ethylhexyl)phthalate in mice. Toxicological Sciences. 2000; 58:377-385.

7. Berman E, Schlicht M, Moser VC and Mac phail RC. A multidisciplinary approach to toxicological screening 1 systemic toxicity. Journal of Toxicology and Environmental Health. 1995: 45:127143.

8. Price S, Ochiend W, Weaver R, Fox G, Mitchell F, Chescoe D and Hinton R. Studies of the mechanism of changes produced in the liver, thyroid, pancreas, and kidney by hypolipidemic drugs and di(2-ethylhexyl)phthalate. In cells, Membranes, and Disease including renal. E. Reid, GM Cook, and JP Luzio, Eds. Plenum press, New York. 1987; pp67-68. 
9. Vanessa C; and Gary W. A review of the health effects of green tea catechins in vivo. Journal of Nutrition. 2004; 134: s34315-34405.

10. Hernandez F; Rodriguez E and Sanche Z. The green tea, a good choice for cardiovascular disease prevention. Archivos Latinoamericanos de Nutrición. 2004; 54:380-394.

11. Yao L; Caffin N; D’ Arcy B; Jiang Y; Shi J; Singanusong R; Liu X; Datta N; Kakuda $\mathrm{Y}$ and $\mathrm{Xu} \mathrm{Y}$. Seasonal variations of phenolic compounds in Australiagrown tea (Camellia sinensis). Journal of Agricultural and Food Chemistry. 2005; 53:6477-6483.

12. Henning SM, Niu Y, Liu Y; Lee NA; Hara Y; Thames GD; Minutti RR; Carpenter CL; Wang $\mathrm{H}$ and Heber D. Bioavailability and antioxidant effect of epigallocatechin gallate administered in purified form versus as green tea extract in healthy individuals. Journal of Nutritional Biochemistry. 2005; 16:610-6.

13. Ahmed A \& Hosney S. Light and electron microscopic study of the effect of furosemide on the liver of white mice. Egyptian Journal of Histolology. 1992; 15 : 357-367.

14. Zhen Y. Ed: Tea-Bioavailability and therapeutic potential . Taylor \& Francis . London. 2002; pp23-58.

15. Schmidt M, Schmitz HJ, Baumgart A, Guedon D, Netsch MI, Kreuter MH, Schmidlin CB, and Schrenk D. Toxicity of Green tea extracts and their constituents in rat hepatocytes in primary culture. Food and Chemical Toxicology. 2005; 43:307314.

16. Pitter $M$ and Ernest E. Systematic review: hepatotoxic events associated with herbal medicinal products. Alimentation in Pharmacology and therapeutics. 2003; 18: $451-471$. 